\title{
Denervação química de interesse clínico - Update
}

\section{Chemical denervation of clinical interest - Update}

DOI: $10.46919 / \operatorname{archv2n6-007}$

Recebimento dos originais: 01/06/2021

Aceitação para publicação: 31/07/2021

\author{
Adriana Novaes Rodrigues \\ Doutora em Ciências Da Saúde \\ Instituição de atuação atual: Universidade de São Paulo \\ Endereço completo: Av Dr Arnaldo 455, Cerqueira Cesar, cep 01246903 \\ E-mail. a.novaes@live.com
}

\section{RESUMO}

A denervação química tem sido utilizada em diversos tratamentos e consiste no bloqueio da transmissão nervosa por algum agente químico. A vasta aplicabilidade, em patologias diversas, requer atualizações frequentes. Objetivo: Rever e condensar as informações, a fim de facilitar a bisca sobre o tema. As buscas foram realizadas em bancos de dados Medline e Lilacs, compreendidos no período de 2009 a 2019. Os descritores utilizados foram: Denervação química, Morte celular, quimiosimpatectomia, em língua portuguesa, inglesa. Resultados: Das 129 referências analisadas, 76 proporcionaram uma visão geral sobre o tema; 15 permitiram a compreensão específica de cada substância, 38 focaram-se no papel em patologias específicas. Conclusões: A necessidade de uma revisão bibliográfica, cria condições para avaliar cada ação em relação a denervação e as patologias.

Palavras-chave: denervação química, Neurotoxina, morte neuronal, quimiosimpatectomia, toxicidade

\begin{abstract}
Chemical denervation has been used in several treatments and consists of blocking nerve transmission by some chemical agent. The wide applicability, in several pathologies, requires frequent updates. Objective: To review and condense the information in order to facilitate the search on the subject. The searches were carried out in Medline and Lilacs databases, from 2009 to 2019. The descriptors used were: Chemical Denervation, Cell Death, Chemosympathectomy, in Portuguese, English language. Results: Of the 129 references analyzed, 76 provided a general overview on the topic; 15 allowed the specific understanding of each substance, 38 focused on the role in specific pathologies. Conclusions: The need for a literature review, creates conditions to evaluate each action in relation to denervation and pathologies.
\end{abstract}

Keywords: chemical denervation, Neurotoxin, neuronal death, chemosympathectomy, toxicity

\section{INTRODUÇÃO}

Animais peçonhentos apresentam misturas únicas e complexas de moléculas bioativas em seu veneno, cujas características são resultaram do processo evolutivo das espécies. As toxinas animais possuem propriedades capazes de interagir com enzimas, receptores e canais iônicos, provocando a desestabilização de sistemas fisiológicos essenciais à sobrevivência das vítimas ou presas (Calvete,2009). 
Apesar de sua toxicidade, alguns componentes isolados dos venenos, podem apresentar potencial terapêutico com atividade antitumoral, antimicrobiano, anticoagulante, e analgésico ( Chan et al., 2016).

A denervação química tem sido utilizada em diversos tratamentos e consiste no bloqueio da transmissão nervosa por algum agente químico. Existem dois tipos de bloqueadores neuromusculares, os despolarizantes e os não-despolarizantes. (Jankovic,2004)

Os bloqueadores neuromusculares despolarizantes agem ao despolarizar a membrana plasmática da fibra muscular, tendo ação semelhante à acetilcolina. No entanto, esses agentes são mais resistentes à degradação pela acetilcolinesterase, a enzima responsável pela degradação da acetilcolina, e podem, portanto, apresentar uma despolarização mais persistente das fibras musculares. Isso difere da acetilcolina, que é rapidamente degradada e despolariza apenas transitoriamente o músculo. E os bloqueadores neuromusculares não-despolarizantes atuam como antagonistas competitivos da acetilcolina no sítio do receptor de acetilcolina pós-sináptico. (Martin et all, 2009). Considerando-se as interações farmacológicas, as toxinas ou substâncias neurotróficas, se tornaram importantes moléculas, mostrando altamente potentes e seletivas, agindo em especial no sistema nervoso (King, 2013).

Quando a devernação química é utilizada para tratamento das patologias já testadas, sua utilização deve ser individualizada, buscando-se otimizá-la para cada paciente e suas necessidades, observando-se os riscos e os benefícios de cada terapia e o melhor momento para utilizá-la. (Saulino et all, 2015)

Devido a vasta aplicabilidade da denervação química, atualizações frequentes são necessárias, sendo assim o objetivo deste trabalho, foi realizar uma revisão científica sobre o tema, considerando suas propriedades químicas, a fim de contribuir para uma condensação e atualização das informações sobre este assunto.

\section{MÉTODO}

Foi realizado uma revisão bibliográfica de literatura especializada. As buscas foram realizadas em bancos de dados, Medline e Lilacs, compreendidos no período de 2009 a 2020. Os descritores utilizados foram: Denervação química, Morte celular, quimiosimpatectomia, em língua portuguesa, inglesa.

\section{RESULTADOS}

Foram selecionados 2188 artigos originais e de revisão que apresentavam os descritores no título. Foi realizado leitura do abstract de todas as publicações selecionadas, sendo descartados 2051 por não serem relevantes a este estudo. Desta seleção, os 137 restantes apresentavam conteúdo potencialmente relevante.

Das 137 referências analisadas, 76 proporcionaram uma visão geral sobre o tema; 18 permitiram a compreensão específica de cada substância, 43 focaram-se no papel em patologias específicas. 


\section{REVISÃO BIBLIOGRÁFICA}

\subsection{SUBSTÂNCIAS NEUROBLOQUEADORAS}

A neurotransmissão é um processo químico que permite a comunicação entre os neurônios e, entre neurônios e células efetoras. Substancias neurobloqueadoras agem nas fibras gama, interrompendo a condução nervosa e o arco reflexo, diminuindo o tônus muscular.

\section{Cloreto de benzalcônio (BZK)}

O Cloreto Benzalcônio (Cloreto de Alquil Dimetil Benzil Amônio) é um conservante biodegradável muito utilizado na farmacologia. Amplamente utilizado como antisséptico cirúrgico, o BZK é um potente detergente catiônico que com propriedades bactericidas e atuando através da destruição da célula bacteriana por toxicidade epitelial. Outra característica importante, é que o CB é um surfactante, com capacidade de reduzir a tensão superficial da água (Baudouin, et al 2010).

O BZK caracteriza-se por apresentar propriedades anti-proliferativas em muitos sistemas celulares, afetando a fase sintética de DNA no ciclo celular, diretamente associado ao zinco (Tzuyoshi et al., 2017). Sua ação do é diretamente proporcional a sua concentração. As soluções aquosas de CB em concentrações elevadas (10\% ou mais) são irritantes para a pele, podendo provocar desde de lesões cutâneas erosivas até necrose profunda. Concentrações baixas $(0,1$ a $0,5 \%)$ podem causar irritação em conjuntiva e em membranas mucosas, e no aparelho gastrointestinal observa-se uma desnervação intrínseca do segmento tratado, com necessidade de adequar a concentração. (Rowe, Sheskey, Quinn, 2009). Vale ressaltar que o zinco potencializa o efeito do CB, o que pode alterar alguns resultados. (Mitani, et all, 2017)

Em relação ao aparelho gastrointestinal, baixas concentrações $(0,3 \%)$ de BZK não danificam a camada muscular lisa intestinal, enquanto que maiores concentrações podem romper as camadas musculares e causar inflamação e perfuração intestinal. Segundo Carvalho et all. (2006), a desnervação mioentérica propicia aumento da área tratada, nas camadas mucosa e muscular, bem como do diâmetro do jejuno. Já a desnervação mioentérica do jejuno associada à ressecção intestinal extensa acarreta melhora do ganho ponderal dos animais. (Carvalho et all., 2006).

\section{6-hidroxidopamina}

Historicamente a 6-hidroxidopamina (6-OHDA) foi identificada há quase 50 anos, sendo muito empregada em modelos experimentais de pesquisa. É uma neurotoxina análoga à dopamina, diferindo por apresentar um grupo hidroxila adicional. A 6-OHDA é seletiva para neurônios dopaminérgicos e neurônios noradrenérgicos, devido à sua alta afinidade por transportadores de dopamina e noradrenalina.(Tieu,2011). O mecanismo de ação descrito da 6-OHDA resume em três etapas, sendo a primeira a formação de peróxido 
de hidrogênio e radicais superóxido; após a formação de peróxido de hidrogênio pela enzima monoaminoxidase e por último a interrupção da cadeia respiratória mitocondrial. (Jagmag, et all. 2016).

Os locais de infusão podem ser três regiões principais: SNpc, feixe prosencefálico medial ou estriado. (Jagmag, et all. 2016). Quando 6-OHDA é infundida no musculo estriado, instaura-se um processo de morte neuronal mais lento com degeneração retrógrada da via nigroestriatal ao longo de três semanas (Tieu, 2011).

O modelo 6-OHDA tem sido utilizado para testar sintomas motores e não motores, como perda da memória, distúrbios do sono e disfunção gastrintestinal, sem comprometimento dos corpúsculos de Lewis. (Jagmag, et all. 2016).

\section{Fenol}

Apesar de ser utilizado há mais de 50 anos em medicina, sua indicação para o tratamento neurológico espástico. Muito utilizado nas décadas de 70 e 80 , foi diminuindo sua aplicabilidade com o advento da toxina botulínica. Seu retorno aos procedimentos de denervação deve-se aos custos do uso de toxina botulínica. (Jozefczyk,2002).

É utilizado como soluções aquosas de fenol entre 3-5\%, podendo chegar a 7\%, (25\% de fenol em $60 \%$ de solução de glicerina diluído em água estéril na concentração de 5\%, tanto nos pontos motores de músculos selecionados, como na região perineural de nervos. (Jozefczyk,2002).

Sua ação neurolítica é usado para o bloqueio de nervos que possuem pequena função sensorial, em pontos motores musculares em casos de espasticidade focal ou multifocal (Jozefczyk,2002).

Quimicamente fenol é todo composto orgânico ácido, que contém uma ou mais hidroxilas $(\mathrm{OH})$ ligadas diretamente a um anel aromático e pouco solúvel em água e solúvel em álcool e éter. Existem duas fases distintas no mecanismo de ação do Fenol: na primeira, o fármaco atua sobre as fibras Gamas causando inativação dos fusos musculares e inibição dos reflexos de estiramento, já na segunda fase ocorre a proteólise, com interrupção dos sinais eferentes das células hiperexcitáveis do corno anterior da medula, levando a degeneração valeriana uma necrose axonal induzida, que corresponde a uma necrose axonal. Esta axoniotmese química, destrói a bainha de mielina das fibras, mas com preservação do tubo endoneural, diminuindo o tônus muscular. (Trevisol et all, 2008).

Está indicada ao bloqueio nos nervos motores, não devendo ser aplicado em nervos mistos, com fibras nervosas sensitivas e motoras, pois a destruição das fibras não é específica, podendo gerar dor. A concentração recomendada é de 5-7\% de Fenol e 45-100\% de álcool. O pico de ação é muito rápido e seu efeito é sentido imediatamente após a aplicação, com duração entre três a 12 meses, que corresponde ao tempo necessário para reconstrução da bainha de mielina (Trevisol et all, 2008). 
Os efeitos colaterais do fenol podem ser descritos como dor, disestesias devido à necrose de axônios sensoriais nos nervos periféricos, letargias e náuseas secundárias à absorção sistêmica e um potencial necrose na região da aplicação (Potasz,2010).

\section{Baclofeno}

O baclofeno é um relaxante muscular central, espasmolítico, derivado do neurotransmissor inibitório GABA, o qual é agonista de receptores GABAb e aumenta o efeito inibitório dos interneurônios. Quando ligado aos receptores, o baclofeno gera uma hiperpolarização da membrana neuronal e reduz o influxo de cálcio nos terminais pré-sinápticos, com a inibição da liberação de neurotransmissores excitatórios e diminuição dos reflexos mono e polissinápticos. Liga-se a receptores GABAb, na membrana pós-sináptica de um canal de cálcio, um canal de potássio permite o fluxo de potássio para fora do terminal resultando em hiperpolarização com interrupção do potencial de ação. Com isto, há uma redução da contração muscular e, consequentemente da espasticidade. O baclofeno é particularmente útil para reduzir a frequência e a severidade de espasmos em flexão ou extensão e reduzir o tônus flexor. (Burchiel e Hsu, 2001)

Sua meia-vida plasmática é de aproximadamente 3-4 h, com excreção renal. Por via intratecal a dose média utilizada varia de 57-187 mcg/dia a 218,7-535,9 mcg/dia. (Wang,et all,2016)

O blacofeno é indicado espasticidade grave, como por esclerose múltipla ou outras doenças do cordão espinhal. Sua finalidade de reduzir ou prevenir as contraturas musculares, facilitando os cuidados em pacientes com incapacidade funcional grave, quando outras formas de tratamento falharam. (Skogberg , et all,2017)

Os efeitos colaterais, como sonolência, insônia, vertigem, astenia, ataxia e confusão mental. De modo semelhante a outros relaxantes musculares, pode prejudicar a deambulação e o equilíbrio, o que limita o seu uso. (Saulino et all,2017)

\section{1-methyl-4-phenyl-1,2,3,6-tetrahydropyridine (MPTP)}

MPTP é uma neurotoxina extremamente lipofílica, que atravessa a barreira hematoencefálica, sendo muito usada em modelos experimentais, cardíacos e é considerada padrão ouro para denervação para pesquisa em modelos experimentais de doença de Parkinson. Convertida em MPP+ pela enzima monoamino oxidase, que está envolvida na degradação das catecolaminas. Este produto, quando acumulado na mitocôndria, inibe o complexo I da cadeia transportadora de elétrons. Sua ação de denervação nas fibras nervosas, tem seu efeito na perda de neurônios dopaminérgicos. (Jackson-Lewis, Blesa e Przedborski ,2012). 
Sua ação está associada ao dano seletivo dos neurônios dopaminérgicos no complexo nigra striatum system, criando distúrbios motores seletivos e perda acentuada de dopamina (DA). A perda de DA acima de 70\%, ocasiona morte da substancia cinzenta, desencadeando os sintomas neurológicos. (Xia, Ye, Shi, et all ,2018) . Estudos experimentais demonstram seletivamente por células monoamínicas, que contém transportadores MPP+, com danos aos nervos simpáticos pós ganglionares. ( Haensch, Lerch , Jörg ,2009)

A desnervação simpática cardíaca no modelo experimental causa lesão ao nervo simpático e depleção norepinefrina, dose dependente, o que deverá requerer outras pesquisas. (Sang-Bin et all 2019)

\section{Neurotoxinas}

Em várias culturas o uso de venenos e peçonhas no tratamento de diversas patologias, principalmente as empregadas no tratamento da dor .A peçonha consiste em uma rica mistura de proteínas e peptídeos com diversas funções biológicas, entre elas as neurotoxinas. Com a função de devernação química podemos citar:

\section{Conotoxinas}

Os caracóis cônicos do gênero Conus usam seus venenos em que seus átomos são compostos principalmente de uma variedade de peptídeos ricos em graxos (conotoxinas) e que têm como ação os canais iônicos da membrana e os receptores de neurotransmissores no sistema nervoso. Como o número de componentes de conotoxina é estimado em mais de 200.000, eles são considerados uma toxina especial para pesquisas para novos medicamentos e tratamento de doenças (Mir,et all,2016)

Conus geographus, é uma espécie de molusco gastrópode marinho, predador, do gênero Conus, pertencente à família Conidae, sendo a espécie mais perigosa para os seres humanos. Responsável por cerca de metade dos envenenamentos humanos conhecidos e quase todas as atualidades, os relatos clínicos falam em "mortes sem dor". Pela falta de especificidade de tecidos e subunidades dos compostos dos Conus e pela presença de antagonistas dos receptores nicotínicos do tipo neuronal, tem gerado interesse nas propriedades analgésicas potenciais do veneno (Dutertre,2014).

Vinte e cinco sequências peptídicas foram derivadas do ducto secretora de veneno de Conus geographus. Alguns desses peptídeos bioativos ( conotoxinas ou conopeptídeos), tem sido correlacionada com os conopeptídeos de veneno do ducto secretório individualmente isolados (DV); com ação neurotóxica, indutoras do bloqueio de receptores sinápticos e causadoras de paralisia muscular miorrelaxante, ocasionando em parada respiratória.(Robinson,2014)

Foram descobertas vinte novas sequências de a-conotoxina sendo que metade delas foram sintetizadas com base na sequência genérica para as a-conotoxinas do tipo neuronal. Foi dada atenção à 
sequência peptídica deduzida Vc1.1 de Conus, pois apresentava a maior semelhança com as a-conotoxinas EpI, MII, PnIA e PnIB, que são antagonistas do receptor nicotínico neuronal (Broxton et al., 2000).

As conotoxinas são produzidas inicialmente como precursores de polipeptídeos codificados em genes e após através de clivagens proteolíticas por modificações pós-traducionais.

Mas existem outras neurotoxinas de interesse das várias superfamílias da espécie Conus. No entanto, as conotoxinas que pertencentes à mesma superfamília não têm necessariamente a mesma estrutura de cisteína ou alvo funcional. Por exemplo ,são as conotoxinas da superfamília “O” que incluem $\omega$ conotoxinas inibidoras do canal $\mathrm{Ca} 2, \mathrm{~K}$-conotoxinas inibidoras do canal $\mathrm{K}$, $\delta$-conotoxinas modificadoras do canal $\mathrm{Na}$ e $\mu \mathrm{O}$-conotoxinas inibidoras do canal $\mathrm{Na}$ (Heinemann et al,2007).Os receptores nicotínicos de acetilcolina (nAChRs) são fundamentais na transmissão de sinais nos sistemas nervoso central e periférico, abrindo os poros seletivos de ativação da ligação da acetilcolina (ACh) ao domínio extracelular(Gotti, et all 2004) Os nAChRs existem como canais homo- ou heteropentaméricos e 17 subunidades foram reconhecidas em espécies de vertebrados $(\alpha 1-\alpha 10, \beta 1-\beta 4, \gamma, \delta$ e $\varepsilon)$. O subtipo nAChR do músculo esquelético é composto pelas subunidades $\alpha 1, \beta 1, \delta$ e $\varepsilon$ (isoforma adulta). Já os subtipos neuronais de nAChR são compostos apenas pelas subunidades $\alpha$ e $\beta$, exceto pelas subunidades $\alpha 7, \alpha 9$ e $\alpha 10$, que podem receber receptores funcionais sem a participação das subunidades $\beta$ (Albuqyerque et all, 2009)

As o-conotoxinas como os primeiros agentes estudados por serem bloqueadores dos canais de cálcio do tipo $\mathrm{N}$ atraíram a atenção como antinociceptivos sendo a MVIIA) recebeu a aprovação do FDA para uso em dores de câncer (Jiang et all, 2017) .

Como o número elevado de componentes da conotoxina, eles são considerados um reservatório para novos medicamentos, em neurociência. (Giordano et all 2014)

\section{Apitoxina}

A apitoxina é veneno das abelhas Apis mellifera, sendo um complexo aquoso, constituído por cerca de 30\% de água (Cruz-Landim, 2009) e vários solutos, principalmente a melitina. Apresenta também uma mistura de proteínas, como as enzimas fosfolipase A2, hialuronidase e fosfatase ácida, os peptídeos melitina, peptídeo MCD, alérgeno $\mathrm{C}$ e as neurotoxinas apamina e histamina aquoso de substâncias formado principalmente por água, aminoácidos, enzimas, proteínas, que atuam principalmente no sistema nervoso (Correia-Oliveira et al., 2012)

A extração da apitotoxina pode ser feita por três maneiras diferentes: forçando a ferroada em uma membrana, separando o ferrão e o veneno, matar a abelha e retirar o veneno por remoção cirúrgica da glândula de veneno, ou utilizar equipamento automatizado, que por impulsos elétricos, que permite obter o veneno livre de impurezas, sem sacrificar abelhas. Este último método, é utilizado como padrão na extração atualmente (Durán et al., 2011). 
Sua ação direta é dose dependente e estimula o fluxo sanguíneo para os tecidos, aumentando a permeabilidade da membrana das células, relaxa os músculos podendo reduzir a dor muscular e estimula a produção de cortisona pelas glândulas suprarrenais, (De-Felice e Padin, 2012). Ensaios in vitro mostraram a capacidade da apitoxina de proteger células de neuroblastoma humano contra MPP+, aumentando a viabilidade das células e agindo de forma anti-apoptótica (Doo et al., 2012). O glutamato, conhecido como o principal neurotransmissor excitatório no sistema nervoso central, desempenha importante papel nas funções cerebrais, como memória, plasticidade sináptica, aprendizagem e cognição. A excitotoxicidade causada pela ativação excessiva e desregulada dos receptores de glutamato pode levar a degeneração neuronal anormal. A apitoxina inibe significativamente a toxicidade celular do glutamato, causando uma desnervação, protegendo contra a morte celular, o que apresenta ser eficaz em doenças neurodegenerativas (Le et al., 2013)

Sua eficiência biológica foi comprovada para diversos usos terapêuticos, como captação antinociceptiva de estímulos nervosos nocivos, analgésico, antitumoral, cicatrizante e neuroprotetor, em doenças como esclerose múltipla, esclerose lateral amiotrófica, doença de Alzheimer e doença de Parkinson (Moreira, 2012).

\section{Neurovespina}

A Neurovespina é um peptídeo sintético modificado a partir da Occidentalina 1202, uma neurotoxina de nove resíduos de aminoácidos isolada da peçonha da vespa social Polybia occidentalis. A Occidentalina-1202, quando injetada por via intracerebroventricular, em ratos, apresenta um potente efeito antiepilético contra crises induzidas por convulsivantes químicos. (Mortari e Cunha 2013). Apresenta um efeito neuroprotetor indireto, pois impede a hiperexcitação e a morte de neurônios em decorrência da excitotoxicidade glutamatérgica (Carneiro,2013). Outra ação da neurovespina é causar contração do músculo liso (útero de rato, jejuno de coelho, íleo de cobaia, cólon de coelho e estômago de sapo), relaxamento do duodeno de ratos (Bockmann e Paegelow, 2000), envolvidas na ativação de leucócitos seguido por uma liberação de citocinas, prostaglandinas, leucotrienos e bloqueio da transmissão colinérgica a nível de SNC de insetos. (Mortari, et all,2007).

Assim, esse peptídeo sintético representa um interessante alvo de estudos farmacológicos para o tratamento de distúrbios neurodegenerativos.

\section{Cnidários}

O Filo Cnidaria inclui as famílias: hidras, águas-vivas, anêmonas-do-mar e corais. São animais que apresentam organização ao nível de tecido, na qual há especialização de células e grupos de células. O que 
define o filo Cnidaria são organelas (Cnidas) especializadas capazes de liberar rapidamente seu conteúdo interno, mediante a ativação dos cnidócitos ,por estímulos externos, mecânicos ou químicos.(Faustin, 2009)

A neurotoxinas de cnidários foi descrita pela primeira vez em 1975 (Béress et al., 1975). A anêmona europeia, Anemonia sulcata, tem como mecanismo de ação retardar a inativação dos canais de $\mathrm{Na}^{+}$ dependentes de voltagem, alterando consequentemente os potenciais de ação (Rathmeyer e Béress, 1976), através de ligação no sítio 3 dos canais de $\mathrm{Na}^{+}$localizados na superfície externa da membrana de neurônios (Caterall e Béress, 1978).

Suas neurotoxinas exibem atividades rápidas e específicas atuando sobre canais iônico. Elas estão contidas em cápsulas de natureza proteica - os nematocistos, que são produtos secretórios do aparelho de Golgi sintetizados por células altamente especializadas chamadas nematócitos (Mariano, et al,2013). A picada de cnidários pode induzir sintomas locais e sistêmicos e representar uma séria ameaça à saúde humana ao longo das costas asiáticas e australianas, bem como em águas oceânicas tropicais, onde águasvivas e anêmonas extremamente venenosas capazes de induzir envenenamentos graves e letais são comuns. O dano induzido por venenos de cnidários foi essencialmente atribuído a um mecanismo de formação de poros ou ao estresse oxidativo.

Várias pesquisas demonstram a importância em relação aos canceres, quando associado a ação de neurotoxicidade do veneno de Cnidários.(Mariottini, et al ,2013)

\section{Snake poison}

Em relação ao envenenamento por cobras, ele é considerado um problema de saúde pública em todo o mundo devido à sua capacidade de causar acidentes graves que podem ser potencialmente letais, com cerca de 81 mil mortes por ano. Devido a esse alto número de acidentes e mortes, o envenenamento por picada de cobra é considerado uma doença tropical negligenciada desde 2017 pela OMS (Chippaux,2017). Porém, os venenos de cobra também são uma mistura de compostos bioativos, que são uma fonte natural de moléculas que têm sido utilizadas como um benefício para a saúde humana. (Yao, et al, 2019)

O veneno de cobra é uma miríade de proteínas e peptídeos biologicamente ativos. As toxinas são altamente conservadas em sua estrutura molecular, mas curiosamente possuem diversas funções biológicas. Pode-se destacara as pesquisas que envolvem tratamentos como câncer patologias de origem neural. Assim, as toxinas podem ser utilizadas como fármacos (ou protótipos para o desenvolvimento de novos fármacos) tanto por sua seletividade quanto por sua potência. (Kodama, et al, 2020)

\section{Crotoxina}

Produzido pelas serpentes do gênero Crotalus (cascavéis), sendo que, na America Latina, CTX corresponde a $60 \%$ do veneno total da Crotalus durissus terrificus. Essa proteína é um complexo 
heterodimérico desenvolvido por uma subunidade básica de atividade fosfolipase A2 (PLA2) conhecida como crotoxina B (CB) e uma subunidade ácida não enzimática que atua como um transportador chamado crotapotina (CA). Estudos farmacológicos revelaram que uma junção neuromuscular é um dos principais níveis de ação dessa toxina, causando paralisia muscular devido a uma soma de efeitos pré e pós-sinápticos. Sua ação pré-sináptica, que atuando nas terminações nervosas, inibe a liberação de acetilcolina. Esta inibição é o principal responsável pelo bloqueio neuromuscular, do qual decorrem as paralisias motoras apresentadas pelos pacientes (Damico, et al 2012). A crotoxina (CTX) é uma neurotoxina $\beta$-heterodimérica formada pela associação não covalente de duas subunidades, uma crotapotina ácida (subunidade CA 9,5 $\mathrm{kDa}$ ) e uma básica (subunidade $\mathrm{CB} \sim 14,5 \mathrm{kDa}$ ) conhecida como fosfolipase A2 (PLA2) 1. e seu peso molecular é de 24 a $26 \mathrm{kDa}$, ponto isoelétrico de 4,7 e exibe atividade fosfolipásica, neurotóxica (bloqueio da transmissão neuromuscular) e miotóxica. (Dias, et al 2016)

A atividade das b-neurotoxinas (toxinas pré-sinápticas) é caracterizada por um efeito trifásico na liberação da acetilcolina (uma diminuição, seguida por um aumento transitório e em seguida, completo bloqueio). (Hodgson e Wickmaratna,2002).

Clinicamente, nas primeiras horas caracterizam o fáscies neurotóxica de Rosenfeld, evidenciadas por ptose palpebral uni ou bilateral, flacidez da musculatura da face, há oftalmoplegia e dificuldade de acomodação (visão turva) ou visão dupla (diplopia) e alteração do diâmetro pupilar (midríase). Raramente podem acometer paralisia velopalatina, com dificuldade à deglutição, diminuição do reflexo do vômito, modificações no olfato e no paladar. (Pinho e Pereira,2001). As neurotoxinas de veneno de serpentes alteram a transmissão no nervo motor terminal tem sido de considerável importância clínica e de pesquisas, porém assumem acentuada importância na última década, pela busca de novas medicações a diversas patologias. (Hodgson e Wickmaratna,2002).

Pesquisas relacionadas a CTX em relação a inativação de células malignas tem sido desenvolvida.

\section{Dendrotoxinas}

As cobras Dendroaspis polylepis ou mamba negra, habitam grande parte da região subsaariana e seu veneno é considerado um dos mais potentes do reino animal. O envenenamento pode causar hipotensão, taquicardia, parestesia em membros superiores e inferiores e insuficiência respiratória em suas vítimas. (Závada, et al,2011) Seu veneno é composto principalmente por moléculas do tipo Kunitz, que incluem dendrotoxinas mamba (63\%), toxinas de três dedos (31\%) e metalopeptidases (3\%). (Laustsen, et al 2015)

Através das moléculas de Kunitz e por adaptações funcionais ação da atividade neurotoxica se dá através de inibidores de protease a neurotoxinas bloqueadoras de canais. Esta ação foi descrita em 2014, por Yang et all, que descreveram o BF9.Este foi o primeiro peptídeo Kunitz de veneno de cobra 
funcionalmente caracterizado com propriedades de inibição de canal de potássio e protease( Yang, et al, 2014)

Kodama, et al (2020), demonstraram que há inibição da elastase-1 e da catepsina L por um peptídeo do tipo Kunitz (Uniprot ID P00979) presente na porção de baixa massa molecular do veneno de D. polylepis. Apesar de já ter sido descrito como uma dendrotoxina, indicando que outras moléculas dessa classe de toxinas podem ter dupla função: bloqueador do canal de potássio e inibidor de protease, outras análises de docking molecular do peptídeo Kunitz com elastase-1, juntamente com o conhecimento da especificidade primária da catepsina L, serviram de base para o desenho racional da PEP2, que se mostrou um inibidor eficiente da catepsina L, com um K i de 1,96 $\mu$ M. (Kodama, et al,2020)

Estes achados têm grande potencial para servir de base para pesquisa de novas moléculas com potencial aplicação biotecnológica.

Em relação ao veneno da Dendroaspis angusticeps ou mamba verde, tem a interessante habilidade de facilitar a liberação de acetilcolina através bloqueio seletivo alguns canais de $\mathrm{K}+$ dependentes de voltagem. Por si essa descoberta teve grande relevância e aplicabilidade para o estudo de excitabilidade celular.

A maioria das dendrotoxinas possui um resíduo de ácido piroglutâmico em seu terminal N. Observase que as $\alpha$-dendrotoxina da mamba verde e dendrotoxina I da mamba negra bloqueiam alguns canais de $\mathrm{K}$ + dependentes de voltagem clonados (Kv1.1, Kv1.2 e Kv1.6) na faixa nanomolar baixa; A dendrotoxina K da mamba negra bloqueia seletivamente os canais Kv1.1 em concentrações picomolares . As interações com proteínas do canal foram estudadas.

O CD-NP baseia-se elegantemente na relação evolutiva das proteínas do corpo da toxina e da toxina. Este peptídeo quimérico de mamba é natriurético de tipo $\mathrm{C}$ humano ou o peptídeo natriurético Dendroaspis. ShK-186 gera centenas de análogos da toxina de bloqueio de canal de K + ShK para melhorar a seletividade e estabilidade do alvo. A desmoteplase é uma forma recombinante do ativador do plasminogênio salivar Desmodus $\alpha 1$ com alta especificidade de fibrina isolada também da saliva do morcego.

\section{Neurotoxina bacteriana}

Sua alta toxicidade aliada a mecanismos de ação extremamente específicos, confere as toxinas bacterianas, características únicas de alta periculosidade, associada a grandes possibilidades de utilização em vários setores clínicos.

\section{Toxina botulínica}

As Neurotoxinas Botulínicas (NTB) são produzidas pela bactéria anaeróbia Clostridium botulinum e são consideradas as toxinas mais potentes conhecidas. (Sposito,2009). 
A desnervação química resultantes da toxina botulínica A (BoNT-A), causa uma paresia temporária, sendo amplamente utilizada em medicina. A mais comum é a do tipo A, que é composta por moléculas não covalentes, ligadas a proteínas não tóxicas, que aumentam o peso molecular total do complexo neurotóxico (Peck el all,2017) .

A parte ativa da molécula da toxina botulínica do tipo-A, BoNT/A, pesa 150kDa e é formada de duas porções: cadeia leve com atividade catalítica $(50 \mathrm{kDa})$, e cadeia pesada $(100 \mathrm{kDa})$. A cadeia leve pesa $50 \mathrm{kDa}$ e é responsável pela atividade metaloproteásica zinco dependente que impede a liberação dos neurotransmissores, através do bloqueio das vesículas de fusão pré-sinápticas. (Zhang et all, 2017)

A cadeia pesada apresenta dois domínios: o de ligação representado por Hc (metade C-terminal da cadeia pesada) e o de translocação representado por Hn (metade N-terminal da cadeia pesada). A cadeia pesada é responsável pela ligação aos receptores extracelulares e internalização na célula nervosa, além de ajudar a translocação da cadeia leve para o citoplasma do neurônio. (Schulte-Baukloh,2004)

O mecanismo de ação evidencia a internalização da toxina 20 min e ela é máxima após 90 min, depois da aplicação. Em seguida ocorre endocitose dentro de vesículas, porém a natureza deste evento ainda é desconhecida. Observa-se em seguida clivagem proteolítica, que acontece dentro da célula nervosa, sob condições de acidificação, liberando a cadeia L catalítica, responsável por bloquear a neuroexocitose, com ação sobre os neurotransmissores, através da atividade de uma endopepdase zinco dependente específica para cada um dos 3 sítios de ligação dentro do sistema neurotóxico sob pH ácido. (Rosen et all,2017).

A TBA age nas proteínas da membrana pré-sinápticas, quebrando a membrana protéica da vesícula sináptica, na SNAP-25 em 3 diferentes pontos de clivagem perto do terminal-C. As Sua ação é uma proteólise seletiva da proteína sináptica SNAP-25, agindo como uma protease zinco dependente. Sendo assim, a SNAP-25 é um resíduo proteico, ligado a superfície da membrana e é requerida no crescimento do axônio. ( Rosen et all,2017).

A função específica destas metaloproteases consiste em auxiliar no duplo reconhecimento dos substratos, baseado na interação com o ponto de clivagem e com o segmento não contínuo que contém a estrutura modificada comum para a VAMP, SNAP-25, e a syntaxin.

A TBA reconhece as estruturas terciárias de seus alvos VAMP, SNAP-25 e syntaxin. Estes alvos compartilham entre si um pequeno trecho de cadeia que aparece em 2 vezes na VAMP, 4 vezes na SNAP25 e 2 vezes na syntaxin. Os peptídeos correspondentes a seqüência específica do "tema principal", nos 3 alvos protéicos, são inibidos in vivo e in vitro pela atividade da neurotoxina, independentemente da sua origem ou tipo. (Zhang et all, 2017)

A parte ativa da molécula da toxina botulínica do tipo-A, BoNT/A, pesa 150kDa e é formada de duas porções: cadeia leve com atividade catalítica $(50 \mathrm{kDa})$, e cadeia pesada $(100 \mathrm{kDa})$. A cadeia leve pesa 50kDa e é responsável pela atividade metaloproteásica zinco dependente que impede a liberação dos 
neurotransmissores, através do bloqueio das vesículas de fusão pré-sinápticas. (Jankovic, 2017). Este o bloqueio não interfere na produção da acetilcolina e por este motivo ele é reversível, após alguns meses Além disto, a demonstração de brotamentos neuronais nos sítios bloqueados parece ser indicativo do esforço natural de reinervação, que garante a reversibilidade do procedimento. (Meunier, et all 2002).

O efeito da toxina botulínica pode ser potencializado por drogas que interferem com a junção neuromuscular. Os antibióticos aminoglicosídeos (kanamicina, gentamicina, estreptomicina), bloqueadores dos canais de cálcio, ciclosporina, aminoquineínas (cloroquina e hidrocloroquina), D-penicilamina, tubocurarina, pancurônio, galamina e succinilcolina.(Hexsel et all, 2000)

\section{CONCLUSÕES}

$\mathrm{Na}$ literatura vigente, os dados mais relevantes e amplamente divulgados estão relacionados a toxina botulínica. Mas muitas outras substâncias são importantes para desenvolvimento de possibilidades de novas terapias medicamentosas a diversas patologias, que requerem bloqueio sináptico. A necessidade de uma revisão bibliográfica, cria condições para avaliar cada ação em relação a denervação e as patologias. 


\section{REFERENCIAS}

1. Albuquerque, E.X.; Pereira, E.F.; Alkondon, M.; Rogers, S.W.(2009) Mammalian nicotinic acetylcholine receptors: From structure to function. Physiol. Rev. 89, 73-120

2. Baudouin, C.; Labbe, A.; Liang, H.; Pauly, A.; Brignole-Baudouin, F. (2010) Preservatives in eyedrops: The good, the bad and the ugly. Prog. Retin. Eye Res. 29, 312-334.

3. Bockmann S, Paegelow I (2000). Kinins and kinins receptors: importance for the activation of leukocytes. Jounal of Leukocyte Biology 68:587-92.

4. Broxton, N., Miranda, L., Gehrmann, J., Down, J., Alewood, P., Livett, B., (2000). Leu10 of aconotoxin PnIB confers potency for neuronal nicotinic responses in bovine chromaffin cells. Eur. J. Pharmacol. 390, 231-238.

5. Burchiel KJ, Hsu FP. (2001) Pain and spasticity after spinal cord injury: mechanisms and treatment. Spine 26(24S):S146-60.

6. Calvete, J. J. Venomics: Digging into the evolution of venomous systems and learning to twist nature to fight pathology. Journal of Proteomics, v. 72, n. 2, p. 121-126, 3/6/ 2009. ISSN 1874-3919. Available at: $<$ http://www.sciencedirect.com/science/article/pii/S1874391909000463 >.

7. Carneiro, L. A. (2013). Avaliação da atividade antiepiléptica e da expressão neuronal de c-fos de dois peptídeos sintetizados a partir da Occidentalina-1202 isolada da vespa social Polybia occidentalis. 2013. 109 f. Dissertação (Mestrado em Biologia Animal) —Universidade de Brasília, Brasília.

8. Carvalho, C.E; Verdiani de, B. F.V. D'A.; Vespúcio, M. V. O.; Iglesias, A. C. G.; Gava, N. F.; Garcia, S.B. (2006) Efeitos da desnervação intrínseca do jejuno após enterectomia extensa na síndrome do intestino curto em ratos. Acta Cir. Bras. [Internet]. Feb [cited 2019 Jun 01] ; 21( 1 ): 43-46. Available from: http://www.scielo.br/scielo.php?script=sci_arttext\&pid=S0102-

9. Chan, Y. S. et al. (2016) Snake venom toxins: toxicity and medicinal applications. Appl Microbiol Biotechnol, v. 100, n. 14, p. 6165-81.

10. Chippaux JP. Snakebite envenomation turns again into a neglected tropical disease! J Venom Anim Toxins incl Trop Dis. 2017; 23:38. doi: 10.1186/s40409-017-0127-6.

11. Correia-Oliveira, M. E., Nunes, L. A., Silveira, T. A., Marchini, L. C. ; Silva, J. W. P. (2012). Manejo da agressividade de abelhas africanizadas. Série Produtor Rural, 1(53):4-46.

12. Cruz-landim, C. (2004). Biologia do Desenvolvimento em abelhas. Depto. Biologia, Instituto de Biociências, Unesp/Rio Claro. Disponível em http://www.rc.unesp.br/ib/biologia/ Carminda.html.

13. Damico, D.C.S., Cruz-Höfling, M.A., Cintra, M., Leonardo, M.B., Calgarotto, A.K., Silva S.L., Marangoni, S., 2008. Pharmacological study of edema and myonecrosis in mice induced by venom of the bushmaster snake (Lachesis muta muta) and its basic Asp49 phospholipase A2 (LmTX-I). Protein J. 27, 384-391.

14. De Felice, Luis J. Padin José. 2012. Apitoxina, su preparado, especificación y farmacología, OMSP. España. 
15. Dias, L., Rodrigues, M. A. P., Rennó, A. L., Stroka, A., Inoue, B. R., Panunto, P. C., Hyslop, S. (2016). Hemodynamic responses to Lachesis muta (South American bushmaster) snake venom in anesthetized rats. Toxicon, 123, 1-14. doi:10.1016/j.toxicon.2016.10.001

16. Doo, A.-R., Kim, S.-T., Kim, S.-N., Moon, W., Yin, C. S., Chae, Y., Park, H.-K., Lee, H. e Park, H.J. 2010. Neuroprotective effects of bee venom pharmaceutical acupuncture in acute 1-methyl-4-phenyl1,2,3,6-tetrahydropyridine-induced mouse model of Parkinson's disease. Neurological Research, 32, 88-91

17. Durán, X. A., Cifuentes, Y. L. \& Morales Ulloa, D. (2011). Evaluación de dos frecuencias de colecta de apitoxina extraída de colmenas de Apis mellifera L. durante la época estival en la Región de La Araucanía. Idesia (Arica), 29(2):145-150

18. Dutertre, S.; Jin, A.H.; Vetter, I.; Hamilton, B.; Sunagar, K.; Lavergne, V.; Dutertre, V.; Fry, B.G.; Antunes, A.; Venter, D.J.; et al. (2014) Evolution of separate predation- and defence-evoked venoms in carnivorous cone snails. Nat. Commun. 5, 3521

19. Fautin, D.G. 2009. Structural diversity, systematics, and evolution of cnidae. Toxicon 54:

20. $1054-1064$.

21. Giordano C, Marchio M, Timofeeva E, Biagini G. Neuroactive peptides as putative mediators of antiepileptic ketogenic diets. Front Neurol 2014; 5: 63.

22. Gotti, C.; Clementi, F.(2004) Neuronal nicotinic receptors: From structure to pathology. Prog. Neurobiol. 74, 363-396

23. Haensch C.A., Lerch H., Jörg J.A., Isenmann S.( 2009). Cardiac denervation occurs independent of orthostatic hypotension and impaired heart rate variability in Parkinson's disease. Parkinsonism Relat. Disord. 15(2):134-137.

24. Heinemann, S.H.; Leipold, E. Conotoxins of the O-superfamily affecting voltage-gated sodium channels. Cell. Mol. Life Sci. 2007, 64, 1329-1340

25. Hexsel D, Mazzuco R, Zechmeister M, Hexsel C. Complications and adverse effects: diagnosis and treatment. In: Hexsel D, Almeida AT. Cosmetic use of botulinum toxin. Porto Alegre: Age; 2000. p.233-9.

26. Hodgson WC, Wickramaratna JC (2002) In vitro neuromuscular activity of snake venoms. Clin Exp Pharmacol Physio 29: 807-814

27. Jackson-Lewis V., Blesa J. e Przedborski S. 2012. Animal models of Parkinson's disease. Parkinsonism Relat. Disord. 18(Suppl.1):183-185. http://dx.doi.org/10.1016/S1353-8020(11)70057-8

28. Jagmag, S.A.; Tripathl, N.; Shukia, S.D.; Sankar, M.; Khurana, S. (2016) Evaluation of Models of Parkinson"s Disease. Frontiers in Neuroscience, v.19, n.9.

29. Jankovic J. Botulinum toxin in clinical practice. J Neurol Neurosurg Psychiatry. 2004;75(7):951-7

30. Jankovic J. Botulinum toxin: state of the art. Mov. Disord. 2017; 32: 1131-1138

31. Jozefczyk PB. The management of focal spasticity. Clin Neuropharmacol. 2002;25(3):158-73. 
32. King, G. (2013). Venoms to drugs: translating venom peptides into therapeutics. Australian Biochemist, 44.

33. Kodama, R; Tadashi, K. A.K; Silva, C. C.F.; Cajado-Carvalho, D.; Duzzi,B. Mariano, D.C.et al . A Kunitz-type peptide from Dendroaspis polylepis venom as a simultaneous inhibitor of serine and cysteine proteases. J. Venom. Anim. Toxins incl. Trop. Dis [Internet]. 2020 [cited 2020 Dec 14] ; 26: e20200037. Available from: http:/www.scielo.br/scielo.php?script=sci_arttext\&pid=S167891992020000100332\&lng=en. Epub Oct 07, 2020. https://doi.org/10.1590/1678-9199-jvatitd-2020-0037.

34. Laustsen AH, Lomonte B, Lohse B, Fernández J, Gutiérrez JM. (2015) Unveiling the nature of black mamba (Dendroaspis polylepis) venom through venomics and antivenom immunoprofiling: Identification of key toxin targets for antivenom development. J Proteomics. Apr 24;119:126-42.

35. Le, W., Sayana, P. ; Jankovic, J.( 2013). Animal Models of Parkinson's Disease: A Gateway to Therapeutics? Neurotherapeutics, 11, 92-110

36. Mariottini, G. L., \& Pane, L. (2013). Cytotoxic and cytolytic cnidarian venoms. A review on health implications and possible therapeutic applications. Toxins, 6(1), 108-151. https://doi.org/10.3390/toxins6010108

37. Marino A., Morabito R., La Spada G. Physiology of Nematocytes; Proceedings of the $83^{\circ}$ Congresso Nazionale SIBS; Palermo, Italy. 24-25 October 2013; Abstract Number 36

38. Martyn JA, Fagerlund MJ, Eriksson LI (2009) Basic principles of neuromuscular transmission. Anaesthesia 64 Suppl 1: 1-9.

39. Meunier FA, Herreros J, Schiavo G, Poulain B, Molgó J.(2002) Molecular mechanism of action of botulinal neurotoxins and the synaptic remodeling they induce in vivo at skeletal neuromuscular junction. In: Massaro EJ. Handbook of neurotoxicology. Totowa: Human Press;. p. 305-47

40. Mir, R.; Karim, S.; Kamal, M.A.; Wilson, C.M.; Mirza, Z. Conotoxins: Structure, therapeutic potential and pharmacological applications. Curr. Pharm. Des. 2016, 22, 582-58 .

41. Mitani, T., Elmarhomy, A. I. E., Dulamjav, L., Anu, E., Saitoh, S., Ishida, S., Oyama, Y. (2017). Zinc-related actions of sublethal levels of benzalkonium chloride: Potentiation of benzalkonium cytotoxicity by zinc. Chemico-Biological Interactions, 268, 31-36. doi:10.1016/j.cbi.2017.02.01 $86502006000100010 \& \operatorname{lng}=$ en.

42. Moreira, D. R. (2012). Apiterapia no tratamento de patologias. Revista Fapciência, 9(4):21-29.

43. Mortari MR, Cunha AO, Ferreira LB, dos Santos WF (2007). Neurotoxins from invertebrates as anticonvulsants: from basic research to therapeutic application. Pharmacology Therapeutic 114(2):171-83

44. Mortari, M. R. ; Cunha, A. O. S. (2013). New Perspectives in Drug Discovery Using Neuroactive Molecules From the Venom of Arthropods, An Integrated View of the Molecular Recognition and Toxinology - From Analytical Procedures to Biomedical Applications, Prof. Gandhi Radis-Baptista (Ed.), ISBN: 978-953-511151-1, InTech.

45. Peck MW, Smith TJ, Anniballi F, Austin JW, Bano L, Bradshaw M, et al. Historical Perspectives and Guidelines for Botulinum Neurotoxin Subtype Nomenclature. Toxins. 2017;9(1):38 
46. Pinho F.M.O., Pereira I.D.. Ofidismo. Rev. Assoc. Med. Bras. [Internet]. 2001 Mar [cited 2020 Jan 05] ; 47( 1 ): 24-29. Available from: http://www.scielo.br/scielo.php?script=sci_arttext\&pid=S010442302001000100026\&lng=en. http://dx.doi.org/10.1590/S0104-42302001000100026.

47. Possani, L. D. Scorpion toxins that cause human intoxication. Toxicon, Oxford, v. 60, n. 2, p. $185-$ $186,2012$.

48. Potasz C. Bloqueios químicos como auxiliares na reabilitação de crianças com paralisia cerebral a importância de uma visão multidisciplinar. Rev Neurocienc. 2010;18(2):172-178.

49. Robinson S.D., et al.Diversity of conotoxin gene superfamilies in the venomous snail, Conus victoriae PLOS ONE, 9 (2014), p. e87648

50. Rosen, O., Feldberg, L., Dor, E., Gura, S., Zichel, R. (2017). Optimization of SNAP-25-derived peptide substrate for improved detection of botulinum A in the Endopep-MS assay. Analytical Biochemistry, 528, 34-37. doi:10.1016/j.ab.2017.04.012

51. Rowe, R.C., Sheskey, P.J., Quinn, M.E. (2009) Handbook of Pharmaceutical Excipients 6th ed. Pharmaceutical Press, London, p. 285.

52. S. Jiang, L. Zhang, X. Pei, F. Deng, D. Hu, G. Chen, C. Wang, K. Hong, X. Yao and H. Gao, Mar. Drugs, 2017, 15, 153, DOI:10.3390/md15060153.

53. Sang-Bin, L; Jinyoung,Y ,Wooyoung, J;Hyun, O.Y (2019) Neuroprotective effect of anodal transcranial direct current stimulation on 1-methyl-4-phenyl-1,2,3,6-etrahydropyridine (MPTP)-induced neurotoxicity in mice through modulating mitochondrial dynamics Neurochemistry International Volume 129 , October 2- 1

54. Saulino M, Ivanhoe C, McGuire J, Ridley B, Shilt J.(2016) Best Practices for Intrathecal Baclofen Therapy: Patient Selection, Neuromodulation: Technology at the Neural Interface, 19, 6, (607-615).

55. Saulino M, Turner M, Miesel K, et al. (2017)Can cerebrospinal fluid pressure detect catheter complications in patients who experience loss of effectiveness with intrathecal baclofen therapy? Neuromodulation 20(2):187-97.

56. Schulte-Baukloh H, Michael TH, Stürzebecher B, Knispel HH.(2014) Botulinum - A toxin detrusor injection as a novel approach in the treatment of bladder spasticity in children with neurogenic bladder. Eur Urol 44(1):139-43.

57. Skogberg O, Samuelsson K, Ertzgaard P, Levi R. (2017)Changes in body composition after spasticity treatment with intrathecal baclofen. J Rehabil Med. 49(1):36-39.

58. Sposito MMM. Toxina Botulínica do tipo A: mecanismo de ação. Acta Fisiatr. 2009;16(1):25-37

59. Terlau, H.; Olivera, B.M. Conus venoms: A rich source of novel ion channel-targeted peptides. Physiol. Rev. 2004, 84, 41-68.

60. Tieu, K. A Guide to Neurotoxic (2011) Animal Models of Parkinson “es Disease. Cold Spring Harb Perspect Med, v. 1, n.1. 
61. Trevisol Bittencourt PC, Tournier MB. Phenol block for spasticity management. Acta Fisiatr. 2008;15(3):189-191.

62. Wang ZM, Law JH, King NK, et al. Treatment of severe, disabling spasticity with continuous intrathecal baclofen therapy following acquired brain injury: the experience of a tertiary institution in Singapore. Singapore Med J. 2016; 57(1):8-12.

63. Xia Yu, Ye Suzhen, Shi Jian, Huang Hanjin. Relationship Between the Anxious Symptoms and the Neurotransmitter in Parkinson's Mice with Different Dosages of MPTP. Braz. arch. biol. technol. [Internet]. 2018 [cited 2020 Jan 01] ; 61: e18160721. Available from: http://www.scielo.br/scielo.php?script=sci_arttext\&pid=S1516-89132018000100315\&lng=en. Epub Nov 14, 2018. http://dx.doi.org/10.1590/1678-4324-2018160721.

64. Yang W, Feng J, Wang B, Cao Z, Li W, Wu Y, et al. BF9, the first functionally characterized snake toxin peptide with Kunitz-type protease and potassium channel inhibiting properties. J Biochem Mol Toxicol. 2014 Feb;28(2):76-83.

65. Yao YT, Yuan X, Fang NX. Hemocoagulase reduces postoperative bleeding and blood transfusion in cardiac surgical patients: A PRISMA-compliant systematic review and meta-analysis. Medicine (Baltimore). 2019 Dec;98(52):e18534

66. Zang,L Masuyer G.Zhang J. Shen Y. Lundin D. Henriksson L. et all, Identification and characterization of a novel botulinum neurotoxin.Nat. Commun. 2017; 8: 14130

67. Závada J, Valenta J, Kopecký O, Stach Z, Leden P. Black mamba dendroaspis polylepis bite: a case report. Prague Med Rep. 2011;112(4):298-304.

68. Zhang S; Masuyer G; Zhang J; Shen Y; Lundin D. et al Identification and characterization of a novel botulinum neurotoxin.Nat. Commun. 2017; 8: 14130 